\title{
Risk factors and outcomes of conversion in minimally invasive distal pancreatectomy: a systematic review
}

\author{
A. Balduzzi ${ }^{1}$ - N. van der Heijde ${ }^{2,3}$ (1) - A. Alseidi ${ }^{4}$ - S. Dokmak ${ }^{5}$ M. L. Kendrick ${ }^{6}$ - P. M. Polanco ${ }^{7}$ - D. E. Sandford ${ }^{8}$. $^{2}$

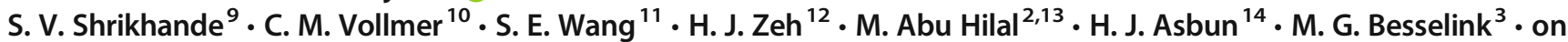 \\ behalf of the International Evidence-based Guidelines of Minimally Invasive Pancreas Resection Group
}

Received: 30 September 2020 / Accepted: 20 November 2020 / Published online: 10 December 2020

(C) The Author(s) 2020

\begin{abstract}
Purpose The reported conversion rates for minimally invasive distal pancreatectomy (MIDP) range widely from 2 to $38 \%$. The identification of risk factors for conversion may help surgeons during preoperative planning and patient counseling. Moreover, the impact of conversion on outcomes of MIDP is unknown.

Methods A systematic review was conducted as part of the 2019 Miami International Evidence-Based Guidelines on Minimally Invasive Pancreas Resection (IG-MIPR). The PubMed, Cochrane, and Embase databases were searched for studies concerning conversion to open surgery in MIDP.

Results Of the 828 studies screened, eight met the eligibility criteria, resulting in a combined dataset including 2592 patients after MIDP. The overall conversion rate was $17.1 \%$ (range 13.0-32.7\%) with heterogeneity between studies associated with the definition of conversion adopted. Only one study divided conversion into elective and emergency conversion. The main indications for conversion were vascular involvement (23.7\%), concern for oncological radicality (21.9\%), and bleeding (18.9\%). The reported risk factors for conversion included a malignancy as an indication for surgery, the proximity of the tumor to vascular structures in preoperative imaging, higher BMI or visceral fat, and multi-organ resection or extended resection. Contrasting results were seen in terms of blood loss and length of stay in comparing converted MIDP and completed MIDP patients.

Conclusion The identified risk factors for conversion from this study can be used for patient selection and counseling. Surgeon experience should be considered when contemplating MIDP for a complex patient. Future studies should divide conversion into elective and emergency conversion.
\end{abstract}

A. Balduzzi and N. van der Heijde shared first authorship

M. Abu Hilal, H. Asbun and M. G. Besselink shared senior authorship

M. G. Besselink

m.g.besselink@amsterdamumc.nl

M. Abu Hilal

abuhila19@gmail.com

H. J. Asbun

horacio.asbun@gmail.com

1 Department of Surgery, University Hospital, Verona, Italy

2 Department of Surgery, Southampton University Hospital, Southampton, UK

3 Department of Surgery, Cancer Center Amsterdam, Amsterdam UMC, University of Amsterdam, Amsterdam, The Netherlands

4 Department of Surgery, University of California, San Francisco, CA, USA

5 Department of Surgery, Beaujon Hospital, Paris, France

6 Department of Surgery, Mayo Clinic, Rochester, MN, USA
7 Department of Surgery, UT Southwestern Medical Center, Dallas, TX, USA

8 Department of Surgery, Washington University, St. Louis, MO, USA

9 Department of Surgery, Tata Memorial Hospital, Mumbai, India

10 Department of Surgery, University of Pennsylvania, Philadelphia, PA, USA

11 Department of Surgery, Taipei Veterans General Hospital and National Yang-Ming University, Taipei, Taiwan, Republic of China

12 Department of Surgery, University of Pittsburgh Medical Center, Pittsburgh, PA, USA

13 Department of General Surgery, Istituto Ospedaliero Fondazione Poliambulanza, Brescia, Italy

14 Hepatobiliary and Pancreas, Miami Cancer Institute, Miami, FL, USA 
Keywords Laparoscopic distal pancreatectomy $\cdot$ Robotic distal pancreatectomy $\cdot$ Conversion to open surgery $\cdot$ Conversion . Minimally invasive distal pancreatectomy

\section{Introduction}

Minimally invasive distal pancreatectomy (MIDP) includes both laparoscopic and robotic distal pancreatectomy. Several reports suggest that MIDP is associated with lower intraoperative blood loss, shorter time to start of oral intake and normal gastrointestinal function, shorter time to functional recovery, and a shorter hospital stay compared with open distal pancreatectomy (ODP) [1-10]. This has been confirmed by two randomized trials on MIDP vs. ODP - the LEOPARD and LAPOP trials $[11,12]$. MIDP, however, remains a technically challenging operation, as shown by the high conversion rates, which range widely from 2 to $38 \%$, even in high-volume centers $[7,13-15]$.

Several studies focused on postoperative morbidity and mortality, as well as oncological outcomes following MIDP. However, data regarding risk factors for conversion and outcomes after conversion are lacking. Conversion, especially when performed as an emergency, may negatively affect short-and long-term outcomes, as shown previously for liver surgery [16]. More data are needed to clarify risk factors and the impact of conversion on outcomes for MIDP. These findings may be relevant not only when comparing surgical series, as patient characteristics may differ between centers and countries, but also for patient selection and counseling for MIDP [17].

To the best of our knowledge, there are no existing systematic reviews that focused on risk factors for conversion in MIDP. The aim of this study was to systematically assess risk factors for conversion during MIDP and the impact of conversion on postoperative outcomes.

\section{Materials and methods}

This systematic review was performed according to the Preferred Reporting Items for Systematic Reviews and Meta-Analysis (PRISMA) guidelines [18] as part of the 2019 Miami International Evidence-Based Guidelines on Minimally Invasive Pancreas Resection (IG-MIPR) [19] and was reported according to the Cochrane Handbook for Systematic Reviews of Interventions [20, 21].

\section{Literature search}

A systematic literature search was conducted with the assistance of a clinical librarian according to the gold standard for systematic reviews in surgery [22]. The PubMed, Embase,
Web of Science, and Cochrane databases were searched until 13 May 2020. Search terms were based on approach (e.g., minimally invasive surgery), procedure (distal pancreatectomy), and on the factors associated with conversion during minimally invasive distal pancreatectomy. The search on PubMed was as follows: "Pancreatectomy"[Mesh] OR "Pancreatic Diseases/surgery"[Mesh] OR pancreat*[tiab]) AND ("Minimally Invasive Surgical Procedures"[Mesh] OR "Laparoscopy"[Mesh] OR "Robotic Surgical Procedures"[Mesh] OR laparoscop*[tiab] OR robotic[tiab] OR robot-assisted[tiab] OR minimally invasive[tiab] OR minimal invas*[tiab] OR hybrid[tiab]) AND ("Conversion to Open Surgery"[Mesh] OR conversion[tiab].

\section{Eligibility criteria}

Studies were included if they reported on factors associated with conversion in MIDP. Studies in languages other than English, duplicates, editorials, and studies on children were excluded. If several studies used the same dataset, only the most recent study was used.

\section{Study selection}

Two authors $(A B$ and $N H)$ independently screened the identified studies. All references of included articles were manually screened for possible additional studies. The first selection was performed based on the title and abstract. Subsequently, the same authors independently performed an assessment of the full text. Any disagreement between the authors was resolved through discussion until a consensus was reached.

\section{Assessment of methodological quality}

The included studies were critically appraised independently by two authors $(A B$ and $N H)$. A quality assessment of the selected studies was performed using the Scottish Intercollegiate Guidelines Network (SIGN) methodology [23]. SIGN was established for the development of evidence-based clinical guidelines. Each study type was assessed with a corresponding checklist, resulting in a quality level of high $(++)$, acceptable $(+)$, low $(-)$, or unacceptable (reject).

The risk of bias was assessed according to the Newcastle Ottawa scale (NOS) for all studies, since no randomized controlled trials (RCT) were expected to be included. A maximum of nine points could be granted, divided equally over three categories-"selection of patients," "comparability," 
and "outcome of study participants." Studies with a NOS score of $\leq 5$ were considered exhibiting a high risk for bias.

\section{Data extraction}

Data extraction was performed according to a predefined evidence table, which was then cross-checked independently by two of the authors $(A B$ and $N H)$. Extracted variables included study design; study period; sample size; patient characteristics (age, sex, BMI, tumor size, diagnosis);operative outcomes; conversion; intraoperative blood loss; operative time; R0 resection margin; and postoperative outcomes such as ClavienDindo grade $\geq 3$ complications, clinically relevant postoperative pancreatic fistula according to the International Study Group on Pancreatic Surgery (ISGPS) definition [24], and length of hospital stay.

\section{Results}

\section{Search results}

A total of 848 studies were identified after duplicates were removed. After the screening of titles and abstracts, 20 studies remained for full-text assessment, of which seven met the eligibility criteria outlined for this review. One additional study was identified after screening the references of the included studies [25]. The PRISMA study selection flow diagram is shown in Fig. 1.

Fig. 1 PRISMA flowchart of all included studies

\section{Methodological quality}

Using the SIGN methodology, two (25\%) of eight studies were considered low quality [26, 27] and the remainder were considered acceptable quality. One (12.5\%) study had a high risk of bias ( $\leq 5$ NOS score) because detailed information on patient follow-up was lacking [26]. Only one study used a form of matching [28].

\section{Definition of conversion}

The characteristics of the included studies are shown in Table 1. Half of the studies did not include a clear definition of conversion [27, 29-31]. Three studies stated that an open conversion was defined as a resection performed via a laparoscopic, robotic, or hand-assisted approach but that an open incision was needed to complete the resection regardless of incision size $[25,26,32]$; two of these studies specifically stated that conversion to a hand-assisted approach was not considered a conversion $[25,26]$. One study categorized conversions as either elective or emergency conversions, the latter due to unexpected events (e.g., bleeding), the former a result of unexpected findings such as tumor extensions to adjacent organs or vascular structures, difficulty in tumor exposure, and adhesions [28].

\section{Indication for conversion}

Five $(62.5 \%)$ studies elaborated on the indications for conversion [25-28, 30]; another study included different types of
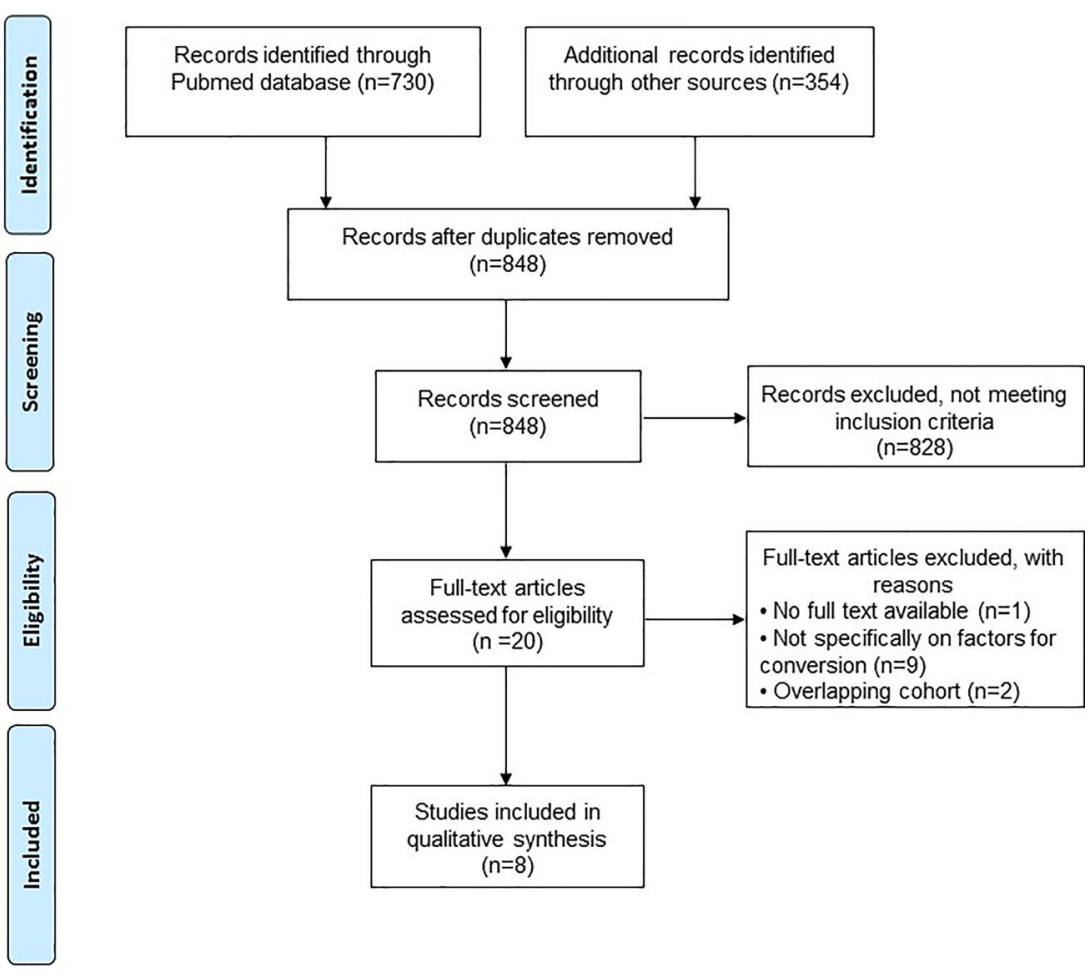
Table 1 Baseline characteristics of the included studies

\begin{tabular}{|c|c|c|c|c|c|c|c|c|}
\hline \multirow[t]{2}{*}{ Study } & \multirow[t]{2}{*}{ Study period } & \multicolumn{2}{|l|}{ Patients $(n)$} & \multirow[t]{2}{*}{ Conversion rate $(\%)$} & \multirow[t]{2}{*}{ Approach } & \multirow[t]{2}{*}{ Single or multicenter } & \multirow[t]{2}{*}{ Study design } & \multirow[t]{2}{*}{ Case matching } \\
\hline & & Converted & Total & & & & & \\
\hline Casadei et al. & 2004-2016 & 13 & 68 & 19.1 & Laparoscopic & Single center & Retrospective & No \\
\hline Goh et al. & 2006-2015 & 10 & 40 & 25.0 & Laparoscopic & Single center & Retrospective & No \\
\hline Hanna et al. & 2006-2012 & 9 & 57 & 15.8 & Robotic & Single center & Retrospective & No \\
\hline Hua et al. & $2007-2015$ & 31 & 211 & 14.7 & Both & Single center & Prospective & No \\
\hline Lee et al. & $2000-2013$ & 55 & 168 & 32.7 & Both & Single center & Prospective & No \\
\hline Lof et al. & 2011-2015 & 68 & 345 & 19.7 & Both & Multicenter & Retrospective & Yes \\
\hline Nassour et al. & 2014-2015 & 231 & 1512 & 15.3 & Both & Multicenter & Prospective & No \\
\hline Partelli et al. & 2015-2018 & 25 & 191 & 13.0 & Laparoscopic & Two centers & Retrospective & No \\
\hline Total & $2000-2018$ & 442 & 2592 & 17.1 & & & & \\
\hline
\end{tabular}

pancreatic resections but did not specify the indications for distal pancreatectomy separately [27]. All indications for conversion in MIDP from the included studies are listed in Table 2. When combining the indications for conversion of all included studies, vascular involvement was the cause that most often led to a conversion ( $n=40,23.7 \%)$, followed by concern for oncological margin $(n=37,21.9 \%)$ and bleeding $(n=32,18.9 \%)$.

\section{Risk factors for conversion}

Six studies assessed the risk factors for conversion [25, 28-32]. An overview of the independent risk factors for conversion from multivariate analyses can be found in Table 3. Three studies assessed both laparoscopic and robotic approaches, two of which found a significantly lower conversion rate for the robotic approach $[28,29]$. Recurrent preoperative risk factors for conversion were obesity, a high BMI (BMI> $30)[28,29]$, or a high amount of visceral fat [25], as well as a preoperative suspicion of a malignancy [30-32]. Intraoperative risk factors included multi-organ resection or a resection extending to neighboring organs [28, 30, 32] and tumor proximity to vascular structures [28, 31]. Other risk factors found were a low preoperative albumin level, a current smoking habit, and chronic pancreatitis [29]. In a univariate logistic regression analysis, Partelli et al. reported that age and the pancreatic resection line (portal vein vs. distal pancreas) are risk factors for conversion [31].

\section{Surgeon procedure volume}

Casadei et al. reported a cutoff to complete the learning curve for laparoscopic distal pancreatectomy (LDP) of 17 procedures. However, the learning curve cutoff was not correlated with the risk of conversion [32]. Two other studies analyzed surgeon experience in relation to conversion. Goh et al. defined a high-volume surgeon as one who performed $>5$ LDPs and found a $10.5 \%$ conversion rate for high-volume surgeons vs. $38.1 \%$ for low-volume surgeons $(p=0.044)$ [26]. Hua et al. defined the case experience of surgeons as either low ( $<15$ LDP cases performed) or high $(\geq 15$ LDP cases performed). They reported a $10.3 \%$ conversion rate for highly experience surgeons vs. $20.2 \%$ for low experience surgeons $(p=0.042)$. In a multivariate analysis, surgeon experience was a significant independent risk factor for conversion (OR 0.32, 95\% CI 0.12-0.85, $p=0.023$ ) [30]. Partelli et al. defined a surgeon's experience as high when they had performed at least 30 LDPs as first operator; $76 \%(n=145)$ of all the cases in their study were with a highly experienced surgeon. Surgeon experience was not a significant risk factor for conversion in univariate regression in their study (OR 0.76, 95\% CI 0.27-2.16, $p=0.609$ ) [31].

\section{Outcomes after conversion}

Nassour et al. [34] compared patient outcomes between those who had MIDP with those who underwent conversion in MIDP and found that the latter group had a longer mean length of hospital stay (mean 8 vs. 6 days, $p<0.001$ ), higher re-operation rate ( $n=15,6.5 \%$ vs. $n=31,2.4 \%)$, and higher 30 -day mortality rate $(n=5,2.2 \%$ vs. $n=4,0.3 \%, p=0.006)$. Converted MIDP also showed a higher rate of re-operation compared with ODP patients $(n=15,6.5 \%$ vs. $n=49,3.5 \%$, $p=0.027)$.

Two other studies also compared the outcome for patients with a conversion with those who had a complete MIDP. The first found that patients with conversion had a higher rate of intraoperative blood loss and transfusion, with comparable pancreatic fistula rates and a longer hospital stay [27]. In contrast, the second found no differences in terms of operation time, blood loss, transfusions, pancreatic fistula, and length of hospital stay [26]. 
Table 2 Indications for conversion in minimally invasive distal pancreatectomy

\begin{tabular}{|c|c|c|c|}
\hline & $\begin{array}{l}\text { Laparoscopy } \\
n(\%)\end{array}$ & $\begin{array}{l}\text { Robot } \\
n(\%)\end{array}$ & $\begin{array}{l}\text { Total } \\
n(\%)\end{array}$ \\
\hline Goh et al. & 10 & - & 10 \\
\hline Oncological concerns & $4(40.0)$ & - & $4(40.0)$ \\
\hline Adhesions & $3(30.0)$ & - & $3(30.0)$ \\
\hline Bleeding & $3(40.0)$ & - & $3(40.0)$ \\
\hline Hua et al. & 36 & - & 36 \\
\hline Obesity & $10(27.8)$ & - & $10(27.8)$ \\
\hline Adhesions & $10(27.8)$ & - & $10(27.8)$ \\
\hline Oncological concerns & $8(14.5)$ & - & $8(14.5)$ \\
\hline Vascular involvement tumor & $6(16.7)$ & - & $6(16.7)$ \\
\hline Bleeding & $2(5.6)$ & - & $2(5.6)$ \\
\hline Lee et al. & 41 & 14 & 55 \\
\hline Obesity & $13(31.7)$ & $4(28.6)$ & $17(30.9)$ \\
\hline Vascular involvement tumor & $12(29.3)$ & $2(14.3)$ & $14(25.5)$ \\
\hline Adhesions & $4(9.6)$ & $2(14.3)$ & $6(10.9)$ \\
\hline Bleeding & $5(12.2)$ & - & $5(9.1)$ \\
\hline Oncological concerns & $3(7.3)$ & $2(14.3)$ & $5(9.1)$ \\
\hline Technical inability to proceed minimally invasive & $3(7.3)$ & $2(14.3)$ & $5(9.1)$ \\
\hline Pancreatic inflammation & - & $2(14.3)$ & $2(5.5)$ \\
\hline Varices & $1(2.4)$ & - & $1(1.8)$ \\
\hline Lof et al. & 67 & 1 & 68 \\
\hline Bleeding & $22(32.8)$ & - & $22(32.4)$ \\
\hline Vascular involvement tumor & $20(29.9)$ & - & $20(29.4)$ \\
\hline Oncological concerns & $19(28.4)$ & $1(100)$ & $20(29.4)$ \\
\hline Adhesions & $4(6.0)$ & - & $4(5.9)$ \\
\hline Poor visualization tumor & $2(3.0)$ & - & $2(2.9)$ \\
\hline Total & 154 & 15 & 169 \\
\hline Vascular involvement tumor & $38(24.7)$ & $2(13.3)$ & $40(23.7)$ \\
\hline Oncological concerns & $34(22.1)$ & $3(20.0)$ & 37 (21.9) \\
\hline Bleeding & $32(20.8)$ & - & $32(18.9)$ \\
\hline Obesity or poor visualization tumor & $25(16.2)$ & $4(26.7)$ & $29(17.2)$ \\
\hline Adhesions & $21(13.6)$ & $2(13.3)$ & $23(13.6)$ \\
\hline Other & $4(2.6)$ & $4(26.7)$ & $8(4.7)$ \\
\hline
\end{tabular}

One study divided conversion into two categories - elective and emergency conversions [28]. A comparison was made between elective and emergency conversions and ODP patients with the use of propensity score matching. Compared to ODP patients, emergency converted patients exhibited a significantly longer operation time (median 285 vs. 240 mins, $p=0.013$ ), higher intraoperative blood loss (median 850 vs. $400 \mathrm{~mL}, p=$ $0.002)$, greater need for blood transfusions ( $n=9,45.0 \%$ vs. $n=3,6.0 \%, p<0.001)$, and a higher rate of minor $(n=16$, $13.1 \%$ vs. $n=10,47.6 \%, p<0.001)$ and overall morbidity $(n=$ $29,47.5 \%$ vs. $n=38,31.1 \%, p=0.030$ ). In contrast, besides differences in average operative time and minor morbidity, there were no significant differences in postoperative outcome between elective converted MIDP and ODP patients [28].

\section{Discussion}

MIDP is increasingly considered the standard approach for patients undergoing distal pancreatectomy in high-volume centers. In this systematic review focusing on risk factors for conversion in MIDP, we found a $17 \%$ overall conversion rate that was affected by several risk factors: smoking, high BMI, preoperative albumin level, malignant disease (T3/T4), chronic pancreatitis, surgeon experience with concurrent vascular resection, and multi-organ resection/extended pancreatic resection. These factors can be considered separately in the preoperative setting.

Numerous studies analyzed the risk factors for conversion in other types of minimally invasive gastrointestinal surgery 
Table 3 Independent risk factors for conversion in minimally invasive distal pancreatectomy

\begin{tabular}{|c|c|c|}
\hline Study & Preoperative risk factors & Intraoperative risk factors \\
\hline $\begin{array}{l}\text { Casadei } \\
\text { et al. }\end{array}$ & None of the factors were significant in multivariable analysis & $\begin{array}{l}\text { Extension of pancreatic } \\
\text { resection }\end{array}$ \\
\hline Goh et al. & Not analyzed & Not analyzed \\
\hline $\begin{array}{l}\text { Hanna } \\
\text { et al. }\end{array}$ & Not analyzed & Not analyzed \\
\hline Hua et al. & $\begin{array}{l}\text { Preoperative diagnosis of malignant disease } \\
\text { Surgeon LDP experience ( } \leq 15 \text { cases })\end{array}$ & $\begin{array}{l}\text { Resection of other organs } \\
\text { required }\end{array}$ \\
\hline Lee et al. & None of the factors were significant in multivariate analysis & Visceral fat \\
\hline Lof et al. & $\begin{array}{l}\text { Tumor proximity to vascular structures }(<1 \mathrm{~cm}) \text { in preopera- } \\
\text { tive imaging }\end{array}$ & Not analyzed \\
\hline $\begin{array}{l}\text { Nassour } \\
\text { et al. }\end{array}$ & $\begin{array}{l}\text { Higher BMI } \\
\text { Higher preoperative albumin level } \\
\text { Current smoking habit } \\
\text { Malignant T3/T4 disease } \\
\text { Chronic pancreatitis }\end{array}$ & Laparoscopic approach \\
\hline $\begin{array}{l}\text { Partelli } \\
\text { et al. }\end{array}$ & Tumor close to vessel $(<2 \mathrm{~cm})$ on preoperative imaging & Not analyzed \\
\hline
\end{tabular}

such as cholecystectomy, nephrectomy, liver, and colorectal surgery [16, 33-39]. The main risk factors identified in these studies were high BMI $[33,38]$, past abdominal infections [37], past abdominal surgery [35], adhesions [34, 38, 39], diagnosis of malignant disease [40], and blood vessel anatomy [38].

Converted MIDP showed a longer operative time and higher intraoperative blood loss, re-operation rate, 30-day mortality, and overall complication compared with ODP. However, differentiating between elective and emergency conversion revealed that elective conversions seem to be comparable to ODP with regard to short-term outcomes, whereas emergency conversions are associated with worse outcomes.

Information regarding the timing of conversion and indication leading to it was often lacking. One might expect that an elective conversion is associated with a smaller, or absent, risk of increased operative time, blood loss, and additional morbidity. Only one study specifically assessed the difference in outcome between elective and emergency conversions and confirmed this hypothesis. Future studies should distinguish between elective and emergency conversions rather than judging conversion as a complication. Currently, a surgeon may lean toward persevering with the MIS approach because of the current bias toward considering conversion a failure. Such a surgical culture may play a role in delaying a conversion when it is needed and may turn an elective conversion into an emergency conversion, with the end result being higher morbidity.
Data concerning the minimum MIDP experience and annual volume per surgeon versus the risk of conversion in MIDP were scarce. The definitions of a "high-volume surgeon" varied widely between 5, 15, and 30 LDPs performed. Considering this range of definitions, it is difficult to compare outcomes between studies. The influence of surgeon experience on conversion was shown in a nationwide study on the impact of a training program that included a detailed description of the technique, video-training and on-site proctoring on MIDP. After the training program, the conversion rate for MIDP decreased from 38 to $8 \%(p<0.001)$ [14]. According to the Miami guidelines on minimally invasive pancreatic resections, depending on the outcome used to assess the learning curve, 10-40 LDP cases are needed to reach proficiency [19]; however, an exact requirement is yet to be defined.

When assessing higher BMI as a risk factor for conversion, the included studies provided conflicting results. This discrepancy could be explained by the fact that BMI might not be an accurate measurement of obesity. It is known that the relationship between visceral fat and BMI differs between men and women; therefore, an intraabdominal fat may be a better method for measuring obesity [41]. Moreover, not all included studies used a clear cutoff for high BMI or it was only specified as "higher BMI" or "BMI per unit increase."

Two previous studies assessed the impact of obesity in MIDP. The first compared obese patients (BMI $\geq 30, n=$ 56) with normal weight (BMI $<25, n=191)$ and overweight patients (BMI 25-29.9, $n=155$ ) and concluded that conversion rates did not differ significantly across 
the three groups $(\mathrm{BMI} \geq 30, n=1 ; 1.8 \%$ vs. $\mathrm{BMI}<25$, $n=1 ; 0.5 \%$ vs. BMI $25-29.9, n=5 ; 3.2 \%, p=0.15$ ) [42]. These outcomes were in line with another study that included 57 nonobese $(\mathrm{BMI}<30)$ and 28 obese patients $(B M I \geq 30)$ who were undergoing robotic distal pancreatectomy. There was no significant difference in conversion rate between the two groups $(\mathrm{BMI}<30: 5.3 \%$ vs. $\mathrm{BMI} \geq 30: 3.5 \% ; p=0.071$ ) [43]. However, both of these studies were retrospective, so there is a high risk of patient allocation bias and other possible confounding factors were not taken into account during the analysis (e.g., no multivariate logistic regression with conversion as a dependent variable was performed). Thus, with the existing literature, it remains unclear whether or not high $\mathrm{BMI}$ is a risk factor for conversion in MIDP.

The results of this study should be assessed with several limitations in mind. First, the number of included studies was low. Since variation may exist between centers and countries, for instance, regarding patients' BMI and surgical volume, more multicenter, and preferably international, studies are needed. Additionally, a uniform cutoff for high-volume MIDP surgeons should be used in future studies to facilitate an assessment of the impact of surgeon experience and center volume on the risk of conversion. Second, the number of indications for MIDP has increased over time, probably due to the growing surgical experience. Third, due to the limited data available, we combined data from laparoscopic and robotic procedures, so it is unclear whether there are different risk factors for these two approaches. Fourth, we did not include Web of Science as a database in our search. Finally, definitions for conversion vary, making it difficult to compare study outcomes. Conversion should be categorized as either emergency or elective conversion to enable a robust comparison between the open approach and total MIDP.

In summary, this study aimed to provide an overview of the current literature for conversion in minimally invasive distal pancreatectomy. Although some risk factors were identified from the included studies, reaching definitive conclusions will require standardization of definitions and data collection protocols in future studies. Larger trials, adjusting for baseline characteristics by using either a form of matching or regression analysis to minimize selection bias, are needed to confirm the findings of this systematic review. Future studies should focus more on the indications for conversion by classifying converted patients into either the elective or emergency conversion group. The Miami guidelines on minimally invasive pancreatic resection recommend the creation of standardized databases to facilitate rigorous study and a deeper understanding of the reasons for conversion in MIDP and their effect on outcomes [19].

\section{Compliance with ethical standards}

The authors declare that they have no conflict of interest. No funding was received for this study. Due to the nature of this study, for which no individual patient data were used, no IRB approval or written informed consent was required.

Open Access This article is licensed under a Creative Commons Attribution 4.0 International License, which permits use, sharing, adaptation, distribution and reproduction in any medium or format, as long as you give appropriate credit to the original author(s) and the source, provide a link to the Creative Commons licence, and indicate if changes were made. The images or other third party material in this article are included in the article's Creative Commons licence, unless indicated otherwise in a credit line to the material. If material is not included in the article's Creative Commons licence and your intended use is not permitted by statutory regulation or exceeds the permitted use, you will need to obtain permission directly from the copyright holder. To view a copy of this licence, visit http://creativecommons.org/licenses/by/4.0/.

\section{References}

1. Rosok BI, de Rooij T, van Hilst J, Diener MK, Allen PJ, Vollmer $\mathrm{CM}$ et al (2017) Minimally invasive distal pancreatectomy. HPB (Oxford) 19(3):205-214

2. Mehrabi A, Hafezi M, Arvin J, Esmaeilzadeh M, Garoussi C, Emami G, Kössler-Ebs J, Müller-Stich BP, Büchler MW, Hackert T, Diener MK (2015) A systematic review and meta-analysis of laparoscopic versus open distal pancreatectomy for benign and malignant lesions of the pancreas: it's time to randomize. Surgery. 157(1):45-55

3. Shakir M, Boone BA, Polanco PM, Zenati MS, Hogg ME, Tsung A, Choudry HA, Moser AJ, Bartlett DL, Zeh HJ, Zureikat AH (2015) The learning curve for robotic distal pancreatectomy: an analysis of outcomes of the first 100 consecutive cases at a highvolume pancreatic centre. HPB (Oxford) 17(7):580-586

4. Venkat R, Edil BH, Schulick RD, Lidor AO, Makary MA, Wolfgang CL (2012) Laparoscopic distal pancreatectomy is associated with significantly less overall morbidity compared to the open technique: a systematic review and meta-analysis. Ann Surg 255(6):1048-1059

5. Nigri GR, Rosman AS, Petrucciani N, Fancellu A, Pisano M, Zorcolo L, Ramacciato G, Melis M (2011) Meta-analysis of trials comparing minimally invasive and open distal pancreatectomies. Surg Endosc 25(5):1642-1651

6. Vijan SS, Ahmed KA, Harmsen WS, Que FG, Reid-Lombardo KM, Nagorney DM, Donohue JH, Farnell MB, Kendrick ML (2010) Laparoscopic vs open distal pancreatectomy: a singleinstitution comparative study. Arch Surg 145(7):616-621

7. Daouadi M, Zureikat AH, Zenati MS, Choudry H, Tsung A, Bartlett DL, Hughes SJ, Lee KK, Moser AJ, Zeh HJ (2013) Robot-assisted minimally invasive distal pancreatectomy is superior to the laparoscopic technique. Ann Surg 257(1):128-132

8. Richardson J, Di Fabio F, Clarke H, Bajalan M, Davids J, Abu HM (2015) Implementation of enhanced recovery programme for 
laparoscopic distal pancreatectomy: feasibility, safety and cost analysis. Pancreatology. 15(2):185-190

9. Abu Hilal M, Hamdan M, Di Fabio F, Pearce NW, Johnson CD (2012) Laparoscopic versus open distal pancreatectomy: a clinical and cost-effectiveness study. Surg Endosc 26(6):1670-1674

10. Abu Hilal M, Takhar AS (2013) Laparoscopic left pancreatectomy: current concepts. Pancreatology. 13(4):443-448

11. de Rooij T, van Hilst J, van Santvoort H, Boerma D, van den Boezem P, Daams F, van Dam R, Dejong C, van Duyn E, Dijkgraaf M, van Eijck C, Festen S, Gerhards M, Groot Koerkamp B, de Hingh I, Kazemier G, Klaase J, de Kleine R, van Laarhoven C, Luyer M, Patijn G, Steenvoorde P, Suker M, Abu Hilal M, Busch O, Besselink M, Dutch Pancreatic Cancer Group (2019) Minimally invasive versus open distal pancreatectomy (LEOPARD): a multicenter patient-blinded randomized controlled trial. Ann Surg 269(1):2-9

12. Björnsson B, Larsson AL, Hjalmarsson C, Gasslander T, Sandström P (2020) Comparison of the duration of hospital stay after laparoscopic or open distal pancreatectomy: randomized controlled trial. Br J Surg. https://doi.org/10.1002/bjs.11554

13. Braga M, Ridolfi C, Balzano G, Castoldi R, Pecorelli N, Di Carlo V (2012) Learning curve for laparoscopic distal pancreatectomy in a high-volume hospital. Updat Surg 64(3):179-183

14. de Rooij T, van Hilst J, Boerma D, Bonsing BA, Daams F, van Dam RM, Dijkgraaf MG, van Eijck C, Festen S, Gerhards MF, Koerkamp BG, van der Harst E, de Hingh IH, Kazemier G, Klaase J, de Kleine RH, van Laarhoven C, Lips DJ, Luyer MD, Molenaar IQ, Patijn GA, Roos D, Scheepers JJ, van der Schelling G, Steenvoorde P, Vriens MR, Wijsman JH, Gouma DJ, Busch OR, Hilal MA, Besselink MG, Dutch Pancreatic Cancer Group (2016) Impact of a nationwide training program in minimally invasive distal pancreatectomy (LAELAPS). Ann Surg 264(5):754-762

15. de Rooij T, Cipriani F, Rawashdeh M, van Dieren S, Barbaro S, Abuawwad M, van Hilst J, Fontana M, Besselink MG, Abu Hilal M (2017) Single-surgeon learning curve in 111 laparoscopic distal pancreatectomies: does operative time tell the whole story? J Am Coll Surg 224(5):826-832 e1

16. Halls MC, Cipriani F, Berardi G, Barkhatov L, Lainas P, Alzoubi M, D'Hondt M, Rotellar F, Dagher I, Aldrighetti L, Troisi RI, Edwin B, Abu Hilal M (2018) Conversion for unfavorable intraoperative events results in significantly worse outcomes during laparoscopic liver resection: lessons learned from a multicenter review of 2861 cases. Ann Surg 268(6):1051-1057

17. Mackay TM, Wellner UF, van Rijssen LB, Stoop TF, Busch OR, Groot Koerkamp B, Bausch D, Petrova E, Besselink MG, Keck T, on behalf of the Dutch Pancreatic Cancer Group and DGAV StuDoQ|Pancreas, van Santvoort HC, Molenaar IQ, Kok N, Festen S, van Eijck CHJ, Bonsing BA, Erdmann J, de Hingh I, Buhr HJ, Klinger C (2019) Variation in pancreatoduodenectomy as delivered in two national audits. Br J Surg 106(6):747-755

18. Liberati A, Altman DG, Tetzlaff J, Mulrow C, Gotzsche PC, Ioannidis JP et al (2009) The PRISMA statement for reporting systematic reviews and meta-analyses of studies that evaluate health care interventions: explanation and elaboration. J Clin Epidemiol 62(10):e1-e34

19. Asbun HJ, Moekotte AL, Vissers FL, Kunzler F, Cipriani F, Alseidi A, D'Angelica MI, Balduzzi A, Bassi C, Björnsson B, Boggi U, Callery MP, del Chiaro M, Coimbra FJ, Conrad C, Cook A, Coppola A, Dervenis C, Dokmak S, Edil BH, Edwin B, Giulianotti PC, Han HS, Hansen PD, van der Heijde N, van Hilst J, Hester CA, Hogg ME, Jarufe N, Jeyarajah DR, Keck T, Kim SC, Khatkov IE, Kokudo N, Kooby DA, Korrel M, de Leon FJ, Lluis N, Lof S, Machado MA, Demartines N, Martinie JB, Merchant NB, Molenaar IQ, Moravek C, Mou YP, Nakamura M, Nealon WH, Palanivelu C, Pessaux P, Pitt HA, Polanco PM, Primrose JN, Rawashdeh A, Sanford DE, Senthilnathan P, Shrikhande SV,
Stauffer JA, Takaori K, Talamonti MS, Tang CN, Vollmer CM, Wakabayashi G, Walsh RM, Wang SE, Zinner MJ, Wolfgang CL, Zureikat AH, Zwart MJ, Conlon KC, Kendrick ML, Zeh HJ, Hilal MA, Besselink MG, International Study Group on Minimally Invasive Pancreas Surgery (I-MIPS) (2020) The Miami International Evidence-based Guidelines on Minimally Invasive Pancreas Resection. Ann Surg 271(1):1-14

20. Higgins JPT, Cochrane C (2020) Cochrane handbook for systematic reviews of interventions.

21. Levin A (2001) The Cochrane collaboration. Ann Intern Med 135(4):309-312. https://doi.org/10.7326/0003-4819-135-4200108210-00035

22. Goossen K, Tenckhoff S, Probst P, Grummich K, Mihaljevic AL, Buchler MW et al (2018) Optimal literature search for systematic reviews in surgery. Langenbeck's Arch Surg 403(1):119-129

23. SIGN Critical appraisal notes and checklists 2019. Available from: https://www.sign.ac.uk/checklists-and-notes

24. Bassi C, Marchegiani G, Dervenis C, Sarr M, Abu Hilal M, Adham M, Allen P, Andersson R, Asbun HJ, Besselink MG, Conlon K, del Chiaro M, Falconi M, Fernandez-Cruz L, Fernandez-del Castillo C, Fingerhut A, Friess H, Gouma DJ, Hackert T, Izbicki J, Lillemoe KD, Neoptolemos JP, Olah A, Schulick R, Shrikhande SV, Takada T, Takaori K, Traverso W, Vollmer CR, Wolfgang CL, Yeo CJ, Salvia R, Buchler M, International Study Group on Pancreatic Surgery (ISGPS) (2017) The 2016 update of the international study group (ISGPS) definition and grading of postoperative pancreatic fistula: 11 years after. Surgery. 161(3):584-591

25. Lee SY, Allen PJ, Sadot E, D'Angelica MI, DeMatteo RP, Fong Y et al (2015) Distal pancreatectomy: a single institution's experience in open, laparoscopic, and robotic approaches. J Am Coll Surg 220(1):18-27

26. Goh BKP, Chan CY, Lee SY, Chan WH, Cheow PC, Chow PKH, Ooi LLPJ, Chung AYF (2017) Factors associated with and consequences of open conversion after laparoscopic distal pancreatectomy: initial experience at a single institution. ANZ J Surg 87(12): E271-E2E5

27. Hanna EM, Rozario N, Rupp C, Sindram D, Iannitti DA, Martinie JB (2013) Robotic hepatobiliary and pancreatic surgery: lessons learned and predictors for conversion. Int J Med Robot 9(2):152159

28. Lof S, Korrel M, van Hilst J, Moekotte AL, Bassi C, Butturini G, Boggi U, Dokmak S, Edwin B, Falconi M, Fuks D, de Pastena M, Zerbi A, Besselink MG, Abu Hilal M (2019) Outcomes of Elective and Emergency Conversion in Minimally Invasive Distal Pancreatectomy for Pancreatic Ductal Adenocarcinoma: An International Multicenter Propensity Score-matched Study. European Consortium on Minimally Invasive Pancreatic Surgery (E-MIPS). Ann Surg. https://doi.org/10.1097/SLA. 0000000000003717

29. Nassour I, Wang SC, Porembka MR, Augustine MM, Yopp AC, Mansour JC, Minter RM, Choti MA, Polanco PM (2017) Conversion of minimally invasive distal pancreatectomy: predictors and outcomes. Ann Surg Oncol 24(12):3725-3731

30. Hua Y, Javed AA, Burkhart RA, Makary MA, Weiss MJ, Wolfgang CL, He J (2017) Preoperative risk factors for conversion and learning curve of minimally invasive distal pancreatectomy. Surgery. 162(5):1040-1047

31. Partelli S, Ricci C, Rancoita PMV, Montorsi R, Andreasi V, Ingaldi C, Arru G, Pecorelli N, Crippa S, Alberici L, Di Serio C, Casadei R, Falconi M (2020) Preoperative predictive factors of laparoscopic distal pancreatectomy difficulty. HPB (Oxford) (12):1766-1774. https://doi.org/10.1016/j.hpb.2020.04.002

32. Casadei R, Ricci C, Pacilio CA, Ingaldi C, Taffurelli G, Minni F (2018) Laparoscopic distal pancreatectomy: which factors are related to open conversion? Lessons learned from 68 consecutive 
procedures in a high-volume pancreatic center. Surg Endosc 32(9): 3839-3845

33. Rosen M, Brody F, Ponsky J (2002) Predictive factors for conversion of laparoscopic cholecystectomy. Am J Surg 184(3):254-258

34. Ercan M, Bostanci EB, Teke Z, Karaman K, Dalgic T, Ulas M, Ozer I, Ozogul YB, Atalay F, Akoglu M (2010) Predictive factors for conversion to open surgery in patients undergoing elective laparoscopic cholecystectomy. J Laparoendosc Adv Surg Tech A 20(5):427-434

35. Masoomi H, Moghadamyeghaneh Z, Mills S, Carmichael JC, Pigazzi A, Stamos MJ (2015) Risk factors for conversion of laparoscopic colorectal surgery to open surgery: does conversion worsen outcome? World J Surg 39(5):1240-1247

36. Eldar S, Siegelmann HT, Buzaglo D, Matter I, Cohen A, Sabo E et al (2002) Conversion of laparoscopic cholecystectomy to open cholecystectomy in acute cholecystitis: artificial neural networks improve the prediction of conversion. World J Surg 26(1):79-85

37. Ishizaki Y, Miwa K, Yoshimoto J, Sugo H, Kawasaki S (2006) Conversion of elective laparoscopic to open cholecystectomy between 1993 and 2004. Br J Surg 93(8):987-991

38. Agha A, Furst A, Iesalnieks I, Fichtner-Feigl S, Ghali N, Krenz D et al (2008) Conversion rate in 300 laparoscopic rectal resections and its influence on morbidity and oncological outcome. Int J Color Dis 23(4):409-417

39. Licciardello A, Arena M, Nicosia A, Di Stefano B, Cali G, Arena G et al (2014) Preoperative risk factors for conversion from laparoscopic to open cholecystectomy. Eur Rev Med Pharmacol Sci $18(2$ Suppl):60-68

40. Shen ZJ, Chen SW, Wang S, Jin XD, Chen J, Zhu Y, Zhang RM (2007) Predictive factors for open conversion of laparoscopic adrenalectomy: a 13-year review of 456 cases. J Endourol 21(11):13331337

41. Park BK, Park JW, Ryoo SB, Jeong SY, Park KJ, Park JG (2015) Effect of visceral obesity on surgical outcomes of patients undergoing laparoscopic colorectal surgery. World J Surg 39(9):2343-2353

42. Sahakyan MA, Rosok BI, Kazaryan AM, Barkhatov L, Lai X, Kleive D et al (2016) Impact of obesity on surgical outcomes of laparoscopic distal pancreatectomy: a Norwegian single-center study. Surgery. 160(5):1271-1278

43. Wang SE, Daskalaki D, Masrur MA, Patton K, Bianco FM, Giulianotti PC (2016) Impact of obesity on robot-assisted distal pancreatectomy. J Laparoendosc Adv Surg Tech A 26(7):551-556

Publisher's note Springer Nature remains neutral with regard to jurisdictional claims in published maps and institutional affiliations. 